\title{
Anabases
}

ANABASES Traditions et réceptions de l'Antiquité

$20 \mid 2014$

Varia

Antonino DE FRANCESCO, The Antiquity of the Italian

Nation. The Cultural Origins of a Political Myth in

Modern Italy 1796-1943

\section{Cyrielle Landrea}

\section{(2) OpenEdition}

Journals

Édition électronique

URL : http://journals.openedition.org/anabases/5148

DOI : 10.4000/anabases.5148

ISSN : 2256-9421

Éditeur

E.R.A.S.M.E.

\section{Édition imprimée}

Date de publication : 1 novembre 2014

Pagination : 409-410

ISSN : 1774-4296

\section{Référence électronique}

Cyrielle Landrea, " Antonino de frAncesco, The Antiquity of the Italian Nation. The Cultural Origins of a Political Myth in Modern Italy 1796-1943», Anabases [En ligne], $20 \mid$ 2014, mis en ligne le 01 novembre 2014, consulté le 22 septembre 2020. URL : http://journals.openedition.org/anabases/5148 ; DOI : https://doi.org/10.4000/anabases.5148

Ce document a été généré automatiquement le 22 septembre 2020

(c) Anabases 


\title{
Antonino DE FRANCESCO, The Antiquity of the Italian Nation. The Cultural Origins of a Political Myth in Modern Italy 1796-1943
}

\author{
Cyrielle Landrea
}

\section{RÉFÉRENCE}

Antonino DE FRANCESCO, The Antiquity of the Italian Nation. The Cultural Origins of a Political Myth in Modern Italy 1796-1943, Oxford, Oxford University Press, 2013, 288 p.

55 livres / ISBN 978-0-19-966231-9

1 L'ouvrage s'inscrit dans le contexte de célébration des cent cinquante ans de l'unification italienne. A. De Francesco propose ainsi de revisiter la culture historique de l'Italie moderne, une culture plurielle, élaborée dès l'Antiquité, grâce à une multitude de peuples italiques. L'approche de l'auteur est résolument pluridisciplinaire; il utilise l'anthropologie, l'archéologie, l'histoire ou encore la paléoethnologie. En outre, la période considérée est vaste, puisqu'elle couvre l'époque napoléonienne jusqu'à la chute de l'idéologie fasciste. Pour cela, il organise sa réflexion avec sept chapitres assortis d'une bibliographie importante (p. 217-249) et d'un index.

2 L'introduction propose une mise en contexte du concept de nation italienne, notamment par rapport au Risorgimento, et son évolution jusqu'à l'époque postcommuniste. L'approche diachronique est donc essentielle. Il n'existe pas un seul nationalisme italien, mais une pluralité de nationalismes.

3 Le premier chapitre («The historic past of the nation ») est une lecture du mythe de l'antiquité du concept national, notamment à travers la figure de Vincenzo Cuoco et de son ouvrage intitulé Platone in Italia (1806). Ce dernier s'inscrit dans un contexte postrévolutionnaire - surtout napoléonien - et tire son origine dans les études antiquaires 
du début de l'ère moderne. Les Étrusques sont ici considérés comme les ancêtres des Italiens et V. Cuoco voulait doter la nouvelle nation italienne de fondements culturels et historiques. L'ouvrage a été critiqué, notamment pour avoir trop mis l'accent sur la primauté culturelle des Italiens.

Dans le deuxième chapitre ("A plural Italy »), A. De Francesco s'intéresse au livre d'un érudit toscan, Giuseppe Micali (Italia avanti il dominio dei romani, 1810), qui met l'accent sur l'ancienneté du haut degré de civilisation atteint par les Italiens avant la domination romaine. V. Cuoco et G. Micali sont liés par un sentiment anti-romain manifeste, mais le second met l'accent sur la pluralité des peuples aux dépens de la primauté culturelle étrusque.

5 Le point de vue de G. Micali a été privilégié par le Risorgimento. D’ailleurs le thème de l'ancienneté de l'Italie avait accompagné le mouvement national de la révolution de 1848. Ainsi dans son chapitre 3 («Unity in diversity »), l'auteur apprécie l'impact des idées de G. Micali sur la culture politique du Risorgimento, notamment dans des espaces (Lombardie, Sicile, Naples) qui de prime abord auraient pu rejeter les idées de G. Micali, tant leurs influences étrangères (gauloises et grecques) furent prégnantes. En fait ses idées furent par exemple appréciées en Lombardie, parce qu'elles permettaient de relancer les aspects celtes et étrusques prégnants dans le nord de l'Italie. Les différentes interprétations de la position de G. Micali confirment que sa lecture est plus culturelle qu'ethnique.

6 L'idée d'une uniformité de la nation italienne et d'une culture commune est rapidement remise en cause après la création de l'État italien. Ainsi dans le chapitre 4 (« The other Italy »), A. De Francesco se focalise sur l'échec du processus de stabilisation dans les régions du sud, au point de voir émerger une Questione meridionale, dont le brigandage en serait une manifestation. Le chapitre s'intéresse alors à l'idée de l'Italia delle piccole patrie, particulièrement en vogue dans le Mezzogiorno et chez les opposants au royaume d'Italie. L'exemple de Giacomo Racioppi est particulièrement développé.

7 Dans le chapitre suivant ("The anthropology of the nation»), A. De Francesco se demande si la difficulté d'intégrer le Mezzogiorno pourrait faire penser à une nature raciste de l'État unifié; une thématique qui se développe peu de temps après 1860 . Cette tendance raciste est illustrée par le développement de nombreuses disciplines, comme la paléoethnologie (Luigi Pigorini), l'archéologie (Edoardo Brizio) et l'anthropologie (Giuseppe Sergi). Par exemple, les travaux de G. Sergi sur la diversité des habitants de la péninsule ont été perçus comme des tendances racistes de l'anthropologie italienne. De même, le sociologue sicilien Alfredo Niceforo a catégorisé les Italiens : ceux du Nord seraient d'origine aryenne, tandis que ceux du sud seraient d'origine méditerranéenne.

Plus globalement, ces disciplines ont ouvert les portes aux composantes ethniques et culturelles du nationalisme italien du début $d u \mathrm{xx}^{\mathrm{e}} \mathrm{s}$. Une des finalités était également de se démarquer du germanisme culturel qui connaissait alors un grand succès.

Le chapitre 6 ( « Return to Rome») propose un état des lieux du renouveau des études sur Rome à travers l'œuvre d'Ettore Pais. Son parcours illustre le cheminement intellectuel de certains savants de son époque. À l'origine admirateur de G. Micali, E. Pais est ensuite fortement influencé par Th. Mommsen pour qui Rome a permis l'unification politique et culturelle de toute l'Italie. En se libérant du poids des autres 
disciplines (anthropologie, archéologie...), E. Pais a également souligné l'analogie entre la Rome ancienne et l'Italie moderne.

10 Ce choix de la romanité comme ancêtre fondateur de l'identité nationale italienne a eu un grand succès à l'époque fasciste. Le dernier chapitre s'intéresse à des aspects déjà largement traités dans l'historiographie («The Italian Fascist Empire, racial policy and Etruscology»). La romanité et l'antiquité de la nation italienne ont souligné la spécificité du modèle romain et justifié la politique expansionniste, comme la guerre d'Ethiopie. Cette dernière était aussi légitimée par une idéologie raciste.

11 A. De Francesco livre donc une synthèse intéressante sur les origines de l'identité ethnique et culturelle de la nation italienne.

\section{AUTEURS}

\section{CYRIELLE LANDREA}

ANHIMA UMR 8210

landrea.cyrielle@wanadoo.fr 